\title{
Energy saving and indoor thermal comfort enhancement by using a novel heat extract slot system installed on external room wall
}

\author{
Ahmed Qasim Ahmed*, Ahmed Jawad Khaleel, H. J Dakkama, \\ Wisam A. M. Al-Shohani \\ Middle Technical University, Technical Engineering College-Baghdad, Baghdad, Iraq
}

\begin{abstract}
Energy saving and indoor thermal environment are affected by many factors such as room direction, internal heat sources and outlet locations. In this paper, the novel method for reducing the effect of heat transfer from the external wall to the office room was presented. In this method, the effect of using a new heat extract slot (HES) system behind the external wall inside the office room and its relation to the amount of extracted air on both energy demand and indoor thermal environment were studied numerically. The proposed system was installed on the external wall which exposures to a high amount of heat. In order to show the performance of using the novel system, four different amounts of extract air, from the exit and HES system were investigated numerically by using the validated CFD model. The result revealed that by using the proposed HES system, a significant enhancement of the energy saving and indoor thermal comfort were achieved. In particular, up to $57 \%$ of energy saving with an acceptable thermal comfort were achieved when only the HES system activated an extracted outlet in the room $(20 \%$ of exhaust air). Thus, $20 \%$ of the exhaust air is the optimum rate of the HES system regarding energy saving and thermal comfort. This will give a significant reduction in energy demand by the cooling coil and enhancing the indoor thermal environment.
\end{abstract}

\section{OPEN ACCESS}

Received: June 9, 2021

Revised: October 9, 2021

Accepted: October 19, 2021

Corresponding Author:

Ahmed Qasim Ahmed aqaa1@mtu.edu.iq

Copyright: The Author(s). This is an open access article distributed under the terms of the Creative Commons Attribution License (CC BY 4.0), which permits unrestricted distribution provided the original author and source are cited.

\section{Publisher:}

Chaoyang University of

Technology

ISSN: 1727-2394 (Print)

ISSN: 1727-7841 (Online)
Keywords: Displacement ventilation, Local extraction, CFD, Energy saving, Thermal comfort.

\section{INTRODUCTION}

The growing demand of energy in buildings and the emission of greenhouse gas are the main problems in the world today (Gillingham et al., 2009). A large amount of the energy is consumed by heating, ventilation and air conditioning (HVAC) systems. This was about $40 \%$ of the total building energy consumption. Therefore, more attention has been paid to reduce the energy demand of the HVAC systems (Pérez-Lombard et al., 2008; Ahmed, 2017). An efficient design of the indoor air distribution system will meet the indoor thermal comfort requirement and reducing the energy demand. Also, the reasonable distribution of the exhaust opening will extract the unwanted warm and pollutants air (Al-Shohani et al., 2020). Where the extraction of the generated heat will improve energy saving by reducing the load on the supply-cooling coil. In addition to the HVAC system features, many other factors should be taken carefully into account by the engineers such as building insulation level, diffuser placement, ratio of the wall to window, area of the external wall, internal obstacle, and buildings orientation (Ahn et al., 2016; Hawendi et al., 2019; Vanhoutteghem et al., 2015; Al-Shohani et al., 2019). In particular, external walls always comprise a large area of the building that is often exposed to the outdoor environment. Although, most external walls are often insulated but a relatively large amount of the heat will transfer through them to the inside. This required extra energy to remove the transferred heat and meet the indoor thermal comfort 
requirement. In the hot countries, the external wall considers one of the significant heat sources that could influence the total cooling load and energy demand. Usually, the inside surface of the external wall is often hottest in the summer compared with other seasons. The hot air from the external wall move along the floor and other bounded walls to reach the extraction opening causing an uncomforted environment for the occupants. In addition, the movement of warm air may increase the draft risk in the occupied zone which leading to human thermal discomfort. Moreover, the energy consumption in office buildings influenced significantly by these external wall properties such as the placement of the air outlet, the contact area, the wall area exposed to the outdoor environment, and the speed of airflow that may increase the transferred heat inside the buildings across the external walls. Generally, the placement of the exit outlet at ceiling level away from the internal heat sources such as external wall, may improve the conditions of the indoor thermal comfort, but this could increase the amount of heat transfer between the interior domain and external wall, due to a large -level thermal convection produced from the external wall. In addition, these placements may not extract efficiently all cumulated warm air from the interior that causes trapped heat that needs more energy to remove the warm air from the indoor space.

Many studies have investigated the impact of exit outlet location on energy demand and indoor thermal comfort. Chiang et al. (2012) investigated the outlet vent placement in the room served by mechanical ventilation and provided information for enhancing the radiant cooling design. They employed two types of diffuser configurations at different positions to show their impact on indoor air distribution and energy saving. Heidarinejad et al. (2015) revealed that the location of the return air vent has a significant impact on the indoor air temperature distribution and energy saving. In addition, they found that the risk of indoor thermal discomfort conditions might be increased by decreasing the height of the return opening. Kuo and Chung (1999) studied the influence of the air outlet position on the indoor thermal comfort conditions and energy saving. They recommended that the installing of the inlet vent on the half-upper wall would help to create a comfortable environment and saving more energy. Lam and Chan (2001) found that the location of the outlet vent has a significant effect on the indoor thermal stratification and indoor cooling load in a gymnasium. Duan and Wang (2019) investigated the interrelation of vent position and exterior window characteristics of indoor thermal conditions and energy consumption. Their results indicate that using the outlet vent near the exterior window will help to enhance the indoor thermal comfort condition and saving more energy. (Ahmed and Gao, 2015; Ahmed et al., 2016) performed a numerical study to find the influence of the combination between the exit outlet and room heat source on the indoor thermal condition and demand of energy. They found that a significant reduction of energy demand was achieved when combined the exhaust opening with room lamps. Another study by Ahmed and Gao (2017); Ahmed et al. (2017) investigated the impact of using the novel local exhaust ventilation (LEV) system on the indoor thermal conditions and energy consumption. Their results found that the exhaust opening location plays a significant role in reducing the energy consumption especially when positioned close to the internal room heat sources. Park and Holland (2001) examined the impact of the internal heat source distribution on temperature distribution and thermal stratification in a room employed a displacement ventilation (DV) system. They revealed that a significant reduction of energy consumption and a good enhancement of the indoor thermal comfort achieved when located the indoor heat sources near the exit vent. Wan and Chao (2005) investigated experimentally the performance of using floor return outlet under different supply temperature and heat load. Their results showed that a good enhancement of the indoor thermal condition with an acceptable energy saving. This was achieved by using the proposed floor return with a temperature air supply at $18^{\circ} \mathrm{C}$. Cheng et al. (2013) performed an experimental and numerical study to show the impact of separating the return and exhaust opening on both indoor thermal comfort and demand on energy. Moreover, the influence of return locations was also investigated. Their results indicated that more energy saving with acceptable thermal comfort conditions was achieved when separate the position of the return and exit outlet a using the proper placement locations. Chen et al. (2013) examined the effectiveness of the air distribution and ventilation system in a low energy building using air for heating and ventilation purpose. They performed different positions of the outlet vent devices under different of outdoor conditions, inside heating load, and airflow rate. Their results showed that the outlet vent plays a main role in improving ventilation and energy consumption. Another study by Gan (1995), he studied the effect of heating and cooling mode on the impact of the supply and exhaust opening placement in terms of energy saving and indoor air quality (IAQ). They found that using an efficient design of the outlet vent distribution will highly improve the energy saving and indoor air quality. Moreover, they concluded that the external wall is considered one of the main heat sources in the buildings during the summer season. In the cooling load calculation, the heat gain from the external wall represents the main source of heat. This was because a large amount of heat will pass through the external wall to the interior, which leads to an increase in the load on the cooling coil of the HVAC system. This percent amount of heat transfer is high in the morning and afternoon. At night, the wall will emit the heat that saved in the wall materials in the morning and afternoon. The emitted heat will also increase the cooling load in buildings at night that required more energy to remove it and provide the required indoor conditions. Therefore, the external wall represents an attractive heat source in the buildings that need more and more investigation. Inadequate studies were performed on how to reduce or 
remove the heat that come from the external wall. Therefore, this study proposed the novel extraction wall slot (HES) system that is employed to remove and extract the heat generated by the external wall under different amounts of extraction air. Thermal comfort requirements were also evaluated for each case study. The extracted heat will reduce the demand for energy by decreasing the load on the cooling coil of the HVAC system. The increasing demand on the energy considers one the main issue that requires solving. In this study, a significant improvement was performed by reducing the demand on energy. The enhancement was achieved by using the HES system give an excellent method to remove the transferred heat from the external wall leads to saving more energy as well as satisfy the thermal comfort requirement. The reason for using HES behind the external is that the external wall is considered the higher temperature wall of the room compared with other walls due to exposition to the outdoor weather conditions like hot ambient air and solar radiation. Recently, the principle of direct heat extraction is a concept that widely investigated and recommended by researchers. Based on the literature, the researchers used the method of HES on different heat sources in the room. However, based on the knowledge of the authors, there is no published work used the HES for the external wall. Therefore, this work presents a novel investigation of using HES for direct heat extraction of the external wall. In this work, a validated CFD model was used to evaluate the performance of using the proposed novel HES system. The relationship between the amount of the extraction air and the HES system was also evaluated. Indoor thermal comfort and energy saving were considered the main assessment indices for this system.

\section{METHODS}

\subsection{Description of the Case Under Study}

The impacts of using the novel HES system on the indoor temperature and velocity distribution, indoor thermal comfort condition and reducing the load on the cooling coil was studied numerically in a small typical room. The working principle of the proposed system is mainly dependent on extracting the generated heat from the external wall. Where, the external wall generates the largest amount of heat due to its location, SE direction, in front of the sun for long period. This heat will transfer through the wall and warming the layer of air neared the wall. Due to the change of air density, buoyancy effect, the warmed air will be moved towards the ceiling. The proposed system will pick up the travelled warm air directly before it mixing with the rest of the room air. For this reason, the HES system was located at the external wall close to the ceiling level. The dimensions of the tested room were $5.0 \mathrm{~m}$ in length, 4.0 $\mathrm{m}$ in width, and $3.0 \mathrm{~m}$ in high. The dimensions of the room external wall, wall exposed to the outdoor environment, was $3.0 \mathrm{~m} \times 5.0 \mathrm{~m}$. Other bounded walls, ceiling and floor assumed an adiabatic wall because these walls are usually represented the internal wall. In order to investigate the influence of the heat source on the proposed HES system, one heat source was used in this study. The employed heat source was located in the room center. Additionally, the proposed HES system was located at the top of the external wall. The dimension of the HES was a long rectangular with dimensions of $0.15 \mathrm{~m} \times 5 \mathrm{~m}$ (see Fig. 1). Table 1 presents the required details of the tested room. In this simulation, the external wall was assumed to be in the direction of the south east (SE) of the building. This direction of the wall allows transferring the largest amount of the heat comparing with other directions. The displacement ventilation (DV) system served the investigated room. The function of the DV system is to provide the supply low air velocity at the floor level, which creates a thermal stratification in the room. In the thermal stratification, the warm air layer is located at the top level while the less warm air layer is located at the floor level. The location of the warm air layer at the top level will help to extract the unwanted warm air from the proposed HES system. For this reason, the DV system was selected in this study. In this investigation, the DV inlet opening was installed near the floor level of the one sidewall. The return opening was installed on the side wall at $1.3 \mathrm{~m}$ from the floor level in front of the DV inlet opening (Cheng et al., 2013). The dimensions of the DV inlet and return opening $(1.2 \mathrm{~m} \times 0.8 \mathrm{~m})$ and $(2.0 \mathrm{~m} \times 0.2 \mathrm{~m})$ respectively. In addition, an exit outlet with dimensions of $0.35 \mathrm{~m} \times 0.35 \mathrm{~m}$ installed at the ceiling corner. In this study, the percentage of the return and extract air was $80 \%$ and $20 \%$ respectively. The test was performed on the extracted air i.e. $20 \%$ of the extraction air. Five different amounts of extraction air were investigated to examine the performance of using the proposed HES system on indoor thermal comfort conditions and energy saving. Table 2 presents the details of the case study considered in this investigation. 


\section{International Journal of Applied Science and Engineering}

Ahmed et al., International Journal of Applied Science and Engineering, 18(6), 2021191
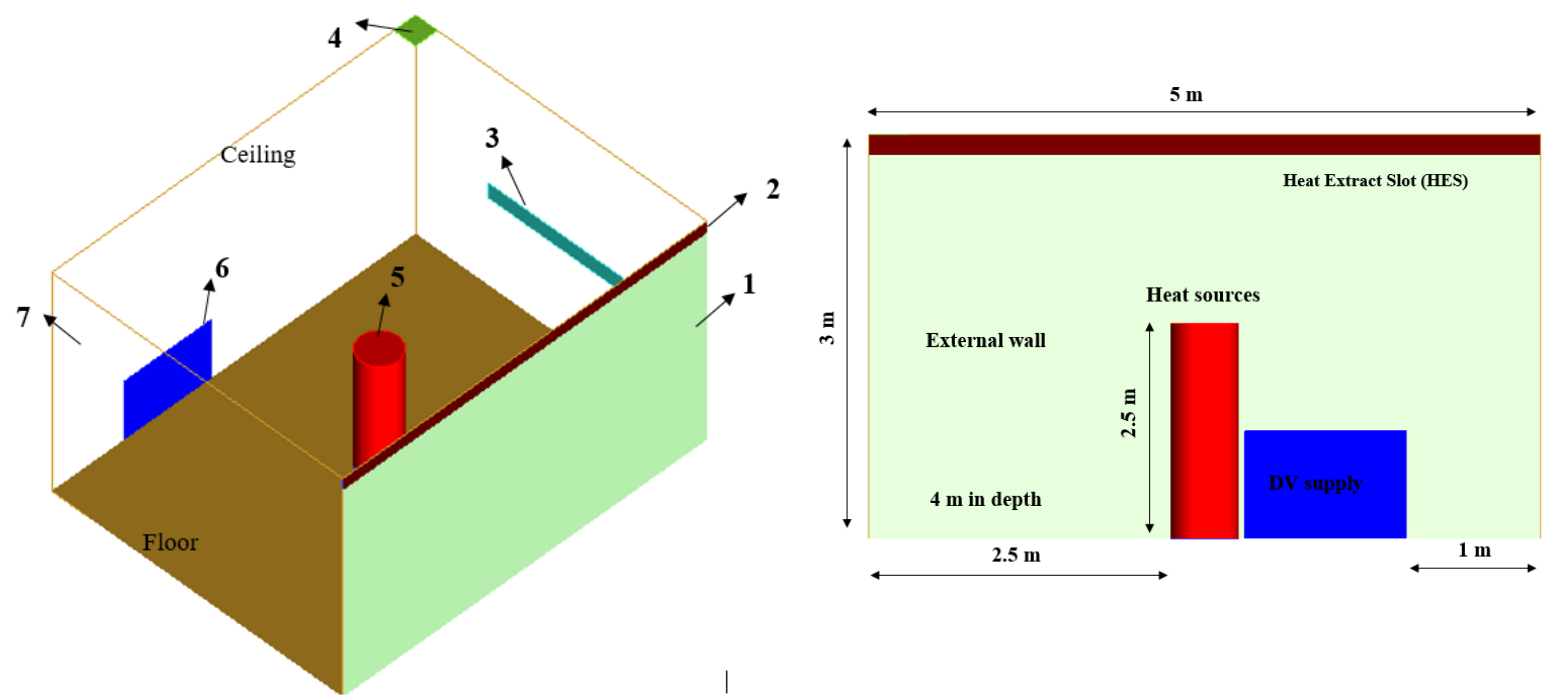

Fig. 1. (a) Configuration of the investigated room; 1- external wall; 2 - heat extracted slot (HES) system; 3 - return inlet; 4- exit inlet; 5- internal heat source; 6- displacement ventilation (DV) supply inlet; 7- adiabatic walls, and (b) the arrangement of the equipment of the tested room

Table 1. Heat sources for the simulated room

\begin{tabular}{cc}
\hline Heat source & Cooling Load (W) \\
\hline Computer & $100 \times 1$ \\
External wall & $90 \mathrm{~W} / \mathrm{m}^{2}$ \\
Bounded walls, ceiling and floor & Adiabatic (internal wall, no heat flux $)$ \\
Total heat flux $\left(\mathrm{Q}_{\text {total }}\right)$ & $1,450 \mathrm{~W}$ \\
\hline
\end{tabular}

Table 2. Case studies details

\begin{tabular}{cccc}
\hline \multirow{2}{*}{ Case study } & \multicolumn{3}{c}{ Percentage of the extracted air (\%) from opening } \\
\cline { 2 - 4 } & Exit outlet & HES & Return \\
\hline Case. 1 & $20 \%$ & $0 \%$ (HES system not used) & $80 \%$ \\
Case. 2 & $15 \%$ & $5 \%$ & $80 \%$ \\
Case. 3 & $10 \%$ & $10 \%$ & $80 \%$ \\
Case. 4 & $0 \%$ (No Exit) & $20 \%$ & $80 \%$ \\
\hline
\end{tabular}

\subsection{Computational Model for the Investigated Room}

For an accurate prediction of the air indoor movement and internal distribution of the air temperature, an efficient turbulence model needs to be chosen from a wide range of existing turbulence models. One of the most trusted turbulence models was the two-equation renormalized group RNG $k-\varepsilon$. It is widely used in such studies because of its ability to predict accurate simulation results of the indoor air movement, temperature distribution, and indoor thermal conditions (Horikiri et al., 2012; Horikiri et al., 2014; Srebric and Chen, 2002; Yuan et al., 1999). For this reason, this model was selected to be the turbulence model of this investigation. RNG $k-\varepsilon$ turbulence model (Equations (1) and (2)) can be written as following (Yakhot et al., 1992):

$\frac{\partial(\rho \mathrm{k})}{\partial \mathrm{t}}+\frac{\partial\left(\rho \mathrm{ku}_{\mathrm{i}}\right)}{\partial \mathrm{x}_{\mathrm{i}}}=\frac{\partial}{\partial \mathrm{x}_{\mathrm{j}}}\left[\left(\mu+\frac{\mu_{\mathrm{t}}}{\sigma_{\mathrm{k}}}\right) \frac{\partial \mathrm{k}}{\partial \mathrm{x}_{\mathrm{j}}}\right]+\mathrm{P}_{\mathrm{k}}+\rho \varepsilon$

$\frac{\partial(\rho \varepsilon)}{\partial \mathrm{t}}+\frac{\partial\left(\rho \varepsilon \mathrm{u}_{\mathrm{i}}\right)}{\partial \mathrm{x}_{\mathrm{i}}}=\frac{\partial}{\partial \mathrm{x}_{\mathrm{j}}}\left[\left(\mu+\frac{\mu_{\mathrm{t}}}{\sigma_{\varepsilon}}\right) \frac{\partial \varepsilon}{\partial \mathrm{x}_{\mathrm{j}}}\right]+\mathrm{C}_{1 \varepsilon} \frac{\varepsilon}{\mathrm{k}} \mathrm{P}_{\mathrm{k}}+\mathrm{C}_{2 \varepsilon}^{*} \rho \frac{\varepsilon^{2}}{\mathrm{k}}$ where

- $\mathrm{C}_{2 \varepsilon}^{*}=\mathrm{C}_{2 \varepsilon}+\left(\mathrm{C}_{\mu} \eta^{3}(1-\eta / \eta \mathrm{o})\right) / 1+\beta \eta^{3}$ with $\eta=$ $(\mathrm{Sk} / \varepsilon)$ and $\mathrm{S}=\sqrt{2 \mathrm{~S}_{\mathrm{ij}} \mathrm{S}_{\mathrm{ij}}}$

The constant values of the RNG $\mathrm{k}-\varepsilon$ turbulence model are shown below:

- $\mathrm{C}_{\mu}=0.0845, \sigma_{\mathrm{k}}=0.7194, \sigma_{\varepsilon}=0.7194, \mathrm{C}_{\varepsilon 1}=$ $1.42, \mathrm{C}_{\varepsilon 2}=1.68$, $\eta \mathrm{o}=4.38$ and $\beta=0.012$.

The CFD program was employed to solve the NavierStokes equations in a 3-D investigated room domain. The ANSYS@FLUENT version R.15.7 was employed in this simulation. Near the wall region, the enhanced wall treatment with required y plus was used in this study. For each case study, a high variation of the air temperature was expected. For this reason, a Boussinesq assumption was activated to calculate the air density the change for each case study. The method for pressure-linked equations (SIMPLE) algorithm was selected for pressure-velocity coupling. Also, second order upwind discretization scheme and PRESTO! 


\section{International Journal of Applied Science and Engineering}

Ahmed et al., International Journal of Applied Science and Engineering, 18(6), 2021191

were employed for this simulation. In addition, the discrete ordinates (DO) method was employed in this study to simulate the radiation influence on the external wall. The detailed information of the selected numerical methods and used boundary conditions are listed in Table 3.

\section{VALIDATION OF THE SELECTED CFD TURBULENCE MODEL}

In order to make sure that the simulation results for this investigation are satisfied the accuracy requirement, a validation work with experimental or analytical study are highly needed. For this study, a comparison was performed between the experimental studies of the previous work with present numerical result. The temperature and the velocity distribution was investigated and measured experimentally in Xu et al. (2009) study. Their results of the temperature and velocity distribution were selected to validate the selected turbulence model for present work. The experimental chamber details and the measured pole location of the tested room that used by the previous work was shown in Fig. 2. Pole 1 and 2 were used to compare the velocity and temperature obtained experimentally by $\mathrm{Xu}$ et al. (2009) with present numerical results (see Fig. 2). According to the Fig. 3, the comparison gives a very good indication on the accuracy between the experimental and numerical study. A numerical calculation was performed to determine the maximum percentage of error for the employed model. The maximum percentage of error was about $2.2 \%$ and $3.1 \%$ for temperature profile and velocity profile respectively. Based on the results in Fig. 3(a) and Fig. $3(b)$, it can be seen that there is a coincide between the experimental and simulation results for many cases. On other hand, there is a limited number of results with difference between the experimental and simulation. This difference of results is widely occurred in the simulation investigations when compared with the experimental demonstration because that the experimental results represent the real airflow behavior and the real distribution of the temperature under test using different measuring instruments and devises like thermometers, anemometers, data loggers, and other devises used in the experimental tests. Moreover, many parameters effects on the uncertainty of these experimental measuring instruments and devises like calibration error, accuracy, resolution, and limits of errors. Based on that, the simulation results will give excellent results with high validity, accuracy, and avoiding the uncertainty of the experimental results.

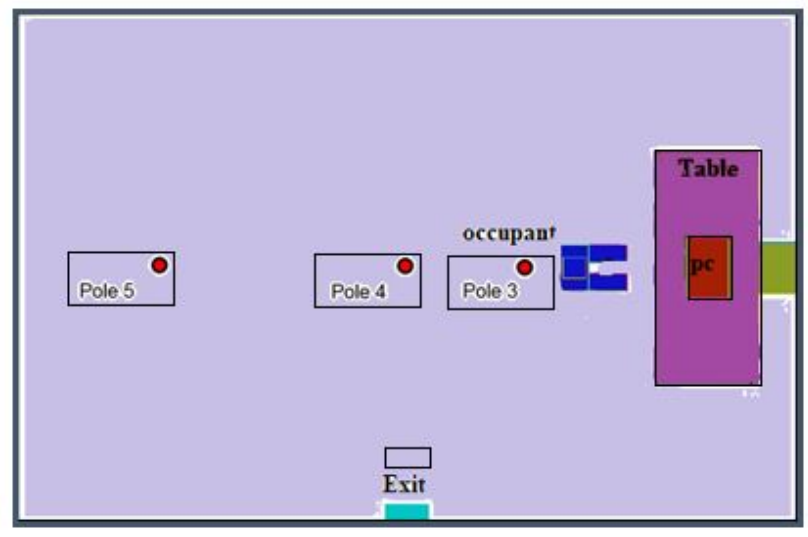

Fig. 2. Top view of the validation room model with poles locations (Xu et al., 2009)

Table 3. Detailed information of the selected numerical methods and used boundary condition

\begin{tabular}{|c|c|}
\hline Turbulence model & RNG $\mathrm{k}-\varepsilon$ \\
\hline Numerical form & Pressure-linked equations (SIMPLE) algorithm, second order upwind \\
\hline $\begin{array}{c}\text { Ceiling, floor, tables and } \\
\text { bounded walls }\end{array}$ & No heat flux $(q=0)$ \\
\hline External wall & Uniform heat flux $90 \mathrm{~W} / \mathrm{m}^{2}$ \\
\hline Supply air & Velocity inlet $\left(0.2 \mathrm{~m} / \mathrm{s}, 19^{\circ} \mathrm{C}\right)$ \\
\hline Return air & Velocity inlet in negative direction $(-0.45 \mathrm{~m} / \mathrm{s})$ \\
\hline HES system & Pressure - outlet \\
\hline Radiation model & The discrete ordinates (DO) method \\
\hline
\end{tabular}




\section{International Journal of Applied Science and Engineering}

Ahmed et al., International Journal of Applied Science and Engineering, 18(6), 2021191
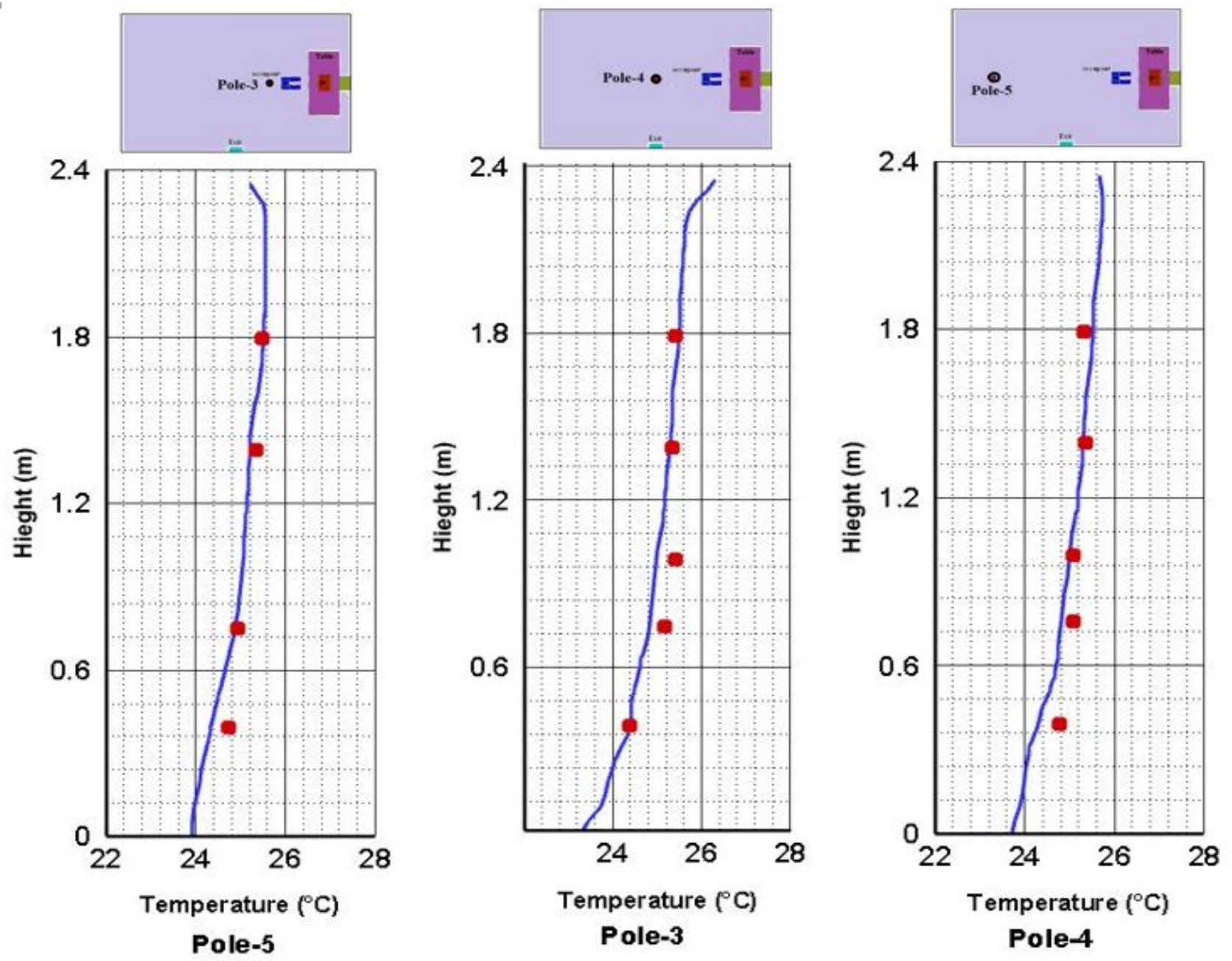

(a) 


\section{International Journal of Applied Science and Engineering}

Ahmed et al., International Journal of Applied Science and Engineering, 18(6), 2021191

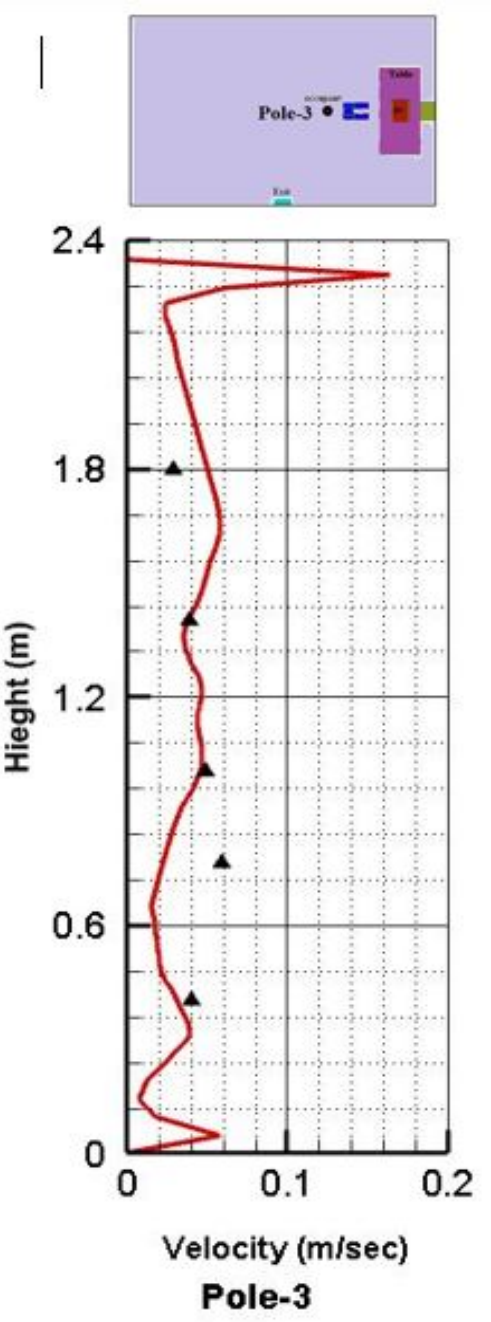

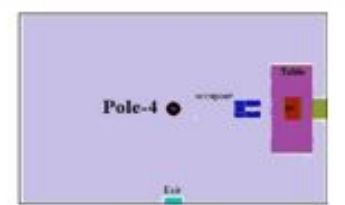

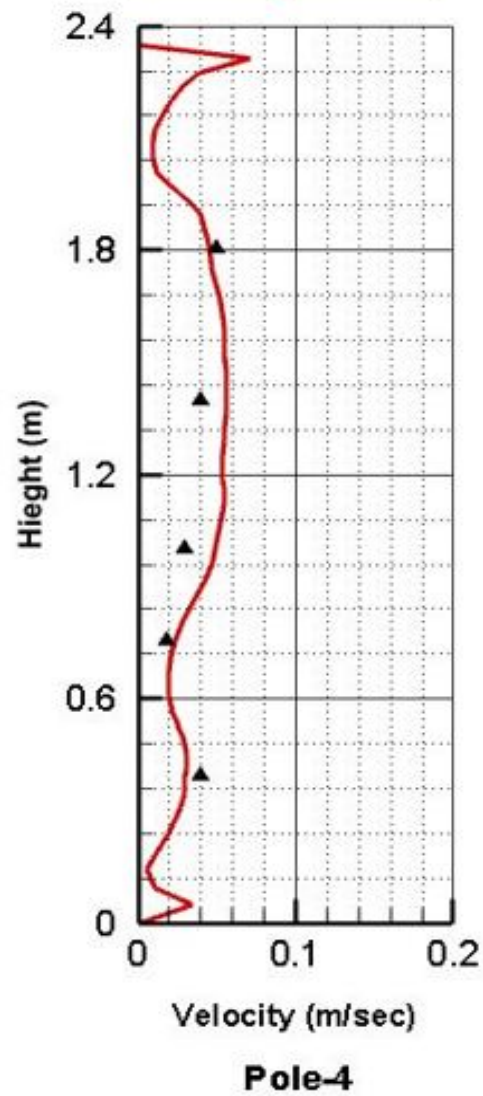

(b)

Fig. 3. Comparison between the experimental and the current simulation results of the temperature and velocity profiles at three vertical poles; (a) temperature distribution and (b) velocity distribution; (dash line: current simulation results and circle symbol: previous experimental results (Xu et al., 2009))

\section{GRID INDEPENDENCE}

In this investigation, ANSYS ICEM CFD was selected to design and generate the mesh. Unstructured tetrahedral grid was employed in this simulation. This type of mesh was very suitable for such complex geometry. In this design, an inflation boundary layers were created near the internal heat sources. A satisfy mesh distribution was used in this investigation and taking in the account the internal and interesting zone. A very fine mesh was generated near the interesting area such as the area around the internal heat source, external wall, and the area close to the proposed extraction system. Less density was used in the area that relatively away from the investigated zone such as an insulated wall, ceiling and floor. This technique will save the simulation time and cost without noticeable change on the accuracy of the results (see Fig. 4). In this investigation, the boundary layer near the external wall is very important.
For this reason, an inflation layer was created near this wall to capture all flow and temperature behavior and to get an accurate evaluation of the proposed ventilation system. Five layers with inflation ratio of 1.2 were used in this study. This will satisfy the required $y+$ value. Mesh test play a central role in any CFD study regarding prediction time and accuracy.

In this simulation, the mesh test was performed to select the proper mesh number depending on comparison simulation results of temperature and velocity for three different sizes (Mesh_A, Mesh_B and Mesh_C), as listed in Table 4. A central point, point located at the room center, was selected to measure the temperature and velocity for each type of mesh. The results show that the difference between Mesh_B and Mesh_C was less than 0.2 for temperature and 0.013 for the velocity. Also, a big difference was found when comparing Mesh_A with Mesh_B and C (see Table 4). In the other ward, the 


\section{International Journal of Applied Science and Engineering}

Ahmed et al., International Journal of Applied Science and Engineering, 18(6), 2021191
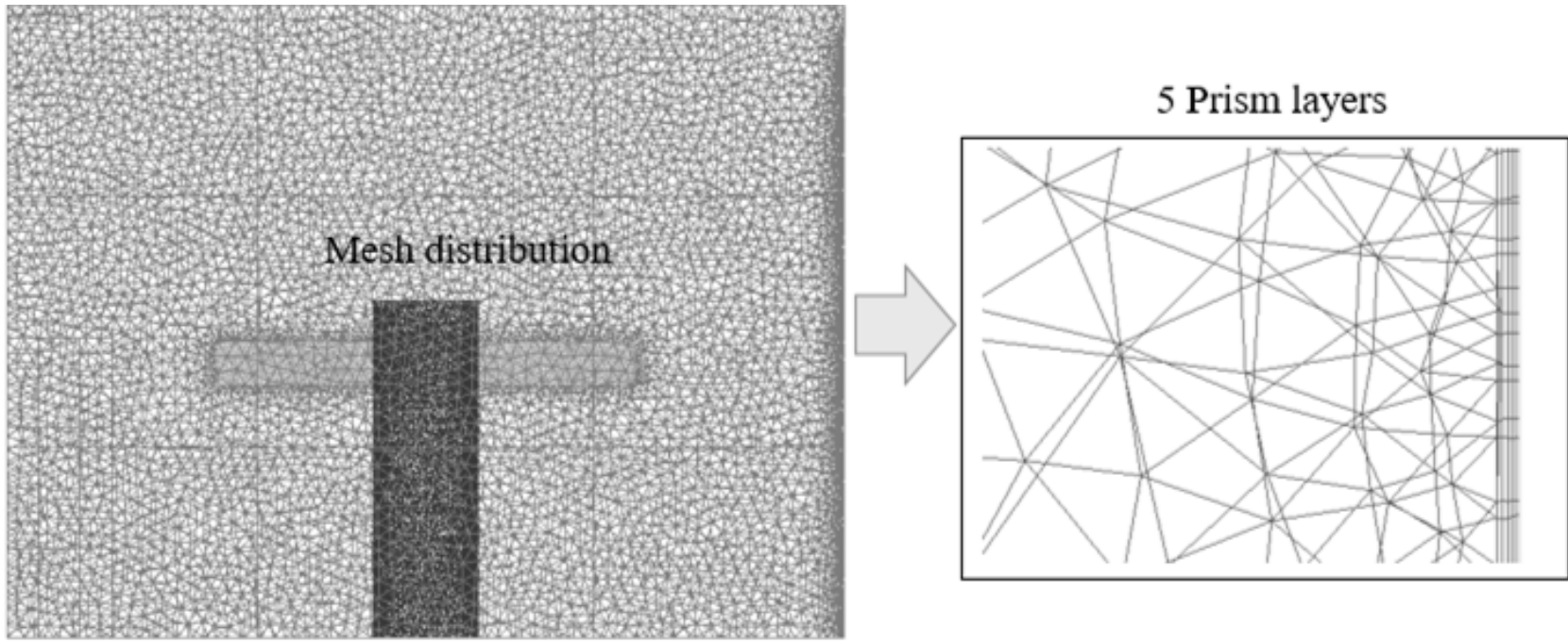

Table 4. Mesh test

\begin{tabular}{cccc}
\hline \multirow{2}{*}{ Mesh types } & \multirow{2}{*}{ Mesh size } & \multicolumn{2}{c}{ Difference } \\
\cline { 3 - 4 } & & Temperature $^{\circ} \mathrm{C}$ & Velocity $(\mathrm{m} / \mathrm{s})$ \\
\hline Mesh_A & 855,240 & 22.54 & 0.0314 \\
Mesh_B & $1,604,677$ & 21.3 & 0.0122 \\
Mesh_C & $2,511,323$ & 21.1 & 0.0135 \\
\hline
\end{tabular}

comparison results found that there is no noticeable change in velocity and temperature profile when increasing the mesh size from Mesh_B to Mesh_C. Therefore, the Mesh_B was selected to be the suitable mesh size for the investigated room.

\section{RESULTS AND DISCUSSION}

In this paper, we use the complexity of the block to determine the hiding bit. More complex block owns more hiding capacity. The strategy solves Lu et al.'s scheme ( $\mathrm{Lu}$ and Leng, 2017) which needs extra recording bit.

The proposed scheme encodes the secret symbols into smaller numbers more effectively. The experimental results show that the hiding performance of the proposed method is higher than that of the other method such as block folding technique (Lu and Leng, 2017) in terms of embedding capacity and image quality.

\subsection{Evaluation of the Indoor Thermal Comfort}

For any ventilation system, it is very important to evaluate the human thermal comfort for the indoor environment. For this reason, the Fanger's comfort equations (Fanger, 1970) was employed in this study as one of the important evaluation indices to show the influence of using the proposed HES system on the indoor thermal comfort. Fanger's comfort equations include two evaluation indices. Predicted mean vote (PMV) and predicted percentage of dissatisfied (PPD), are the two indices that represent the thermal balance of the whole occupant body. The PMV can be defined as the mean value of the votes of occupants under the same thermal conditions on seven levels of the human thermal sensation listed in Table 5. While the PPD index can be defined as the percentage of occupants in a large group which they are tended to thermally discomfort under specific thermal conditions. In order to provide an acceptable indoor thermal comfort, the required value for the PMV and PPD indices should be in the range $0.5<\mathrm{PMV}<0.5$ and $\mathrm{PPD}<10$ percent respectively. The indices of PMV and PPD can be expressed by Equations (3) and (4) (Fanger, 1970):

Table 5. Thermal sensation scale

\begin{tabular}{cc}
\hline PMV. & Thermal sensation \\
\hline+3 & Hot \\
+2 & Warm \\
+1 & Slightly warm \\
0 & Neutral \\
-1 & Slightly cool \\
-2 & Cool \\
-3 & Cold \\
\hline
\end{tabular}




\section{International Journal of Applied Science and Engineering}

Ahmed et al., International Journal of Applied Science and Engineering, 18(6), 2021191

$$
\begin{aligned}
& \mathrm{PMV}=\left(0.03 \mathrm{e}^{-0.036 \mathrm{M}}+0.028\right)\left\{(\mathrm{M}-\mathrm{W})-3.05 \times 10^{-3} \times\left[5733-6.99(\mathrm{M}-\mathrm{W})-\mathrm{p}_{\mathrm{a}}\right]-0.42 \times[(\mathrm{M}-\mathrm{W})-58.15]\right. \\
&-1.7 \times 10^{-5} \mathrm{M}\left(5867-\mathrm{p}_{\mathrm{a}}\right)-0.0014 \mathrm{M}\left(34-\mathrm{t}_{\mathrm{a}}\right)-3.96 \times 10^{-8} \mathrm{f}_{\mathrm{cl}} \times\left[\left(\mathrm{t}_{\mathrm{cl}}+273\right)^{4}-\left(\overline{\mathrm{t}}_{\mathrm{r}}+273\right)^{4}\right] \\
&\left.-\mathrm{f}_{\mathrm{cl}} \mathrm{h}_{\mathrm{c}}\left(\mathrm{t}_{\mathrm{cl}}-\mathrm{t}_{\mathrm{a}}\right)\right\}
\end{aligned}
$$

where

$\mathrm{t}_{\mathrm{cl}}=35.7-0.028(\mathrm{M}-\mathrm{W})-\mathrm{c}_{\mathrm{cl}}\left\{3.96 \times 10^{8} \mathrm{f}_{\mathrm{cl}} \times\left[\left(\mathrm{t}_{\mathrm{cl}}+273\right)^{4}-\left(\mathrm{t}_{\mathrm{r}}+273\right)^{4}\right]+\mathrm{f}_{\mathrm{cl}} \mathrm{h}_{\mathrm{c}}\left(\mathrm{t}_{\mathrm{cl}}-\mathrm{t}_{\mathrm{a}}\right)\right\}$

and $\mathrm{f}_{\mathrm{cl}}\left\{\begin{array}{ll}1+1.290 \mathrm{I}_{\mathrm{cl}} \\ 1.05+0.645 \mathrm{I}_{\mathrm{cl}}\end{array}\right.$ for $\begin{cases}\mathrm{I}_{\mathrm{cl}} \leq 0.078 & \left(\mathrm{~m}^{2}{ }^{\circ} \mathrm{C} / \mathrm{W}\right) \\ \mathrm{I}_{\mathrm{cl}}>0.078 & \left(\mathrm{~m}^{2}{ }^{\circ} \mathrm{C} / \mathrm{W}\right)\end{cases}$

and $\mathrm{h}_{\mathrm{c}}\left\{\begin{array}{ll}2.38\left(\mathrm{t}_{\mathrm{cl}}-\mathrm{t}_{\mathrm{a}}\right)^{0.25} \\ 12.2 \sqrt{\mathrm{var}_{\mathrm{ar}}}\end{array}\right.$ for $\begin{cases}2.38\left(\mathrm{t}_{\mathrm{cl}}-\mathrm{t}_{\mathrm{a}}\right)^{0.25} & >12.1 \sqrt{\mathrm{var}} \\ 2.38\left(\mathrm{t}_{\mathrm{cl}}-\mathrm{t}_{\mathrm{a}}\right)^{0.25} & <12.1 \sqrt{\mathrm{var}_{\mathrm{ar}}}\end{cases}$

Then

$\mathrm{PPD}=100-95 \times \mathrm{e}^{-\left(0.03353 \times \mathrm{PMV}^{4}+0.2179 \times \mathrm{PMV}^{2}\right)}$

In this paper, all case studies were evaluated using the PMV and PPD evaluation indices. The results of the PMV and PPD were compared and presented in Fig. 5 and Fig. 6 respectively. Four different amounts of the extracted air from the exit and HES outlet were examined (see Table 2). For all case studies, the PMV and PPD values were in the required acceptance range (between 0 and $<-0.5$ for the PMV and below 10\% for the PPD) (see Fig. 5 and Fig. 6). Also, it is clear that a relatively high range of PMV and PPD were found in case 1 . This was due to that case 1 represents the reference case i.e. room without using the proposed HES system. In this case, case.1, the exhausted warm air was only extracted from the exit opening. This will need more time to reach the warm air to the exit comparing with case 2, 3 and 4.

Generally, the warm air generated by the internal room heat sources plays a central role in forming the indoor thermal environment. In most cases, the smooth extraction of the generated warm air will improve and enhance the indoor thermal comfort. In cases 1, 2, and 3 when the HES system was installed, the PMV and PPD values were relatively better than in case 4 . This was because that a large amount of the warm air coming from the external wall will extract directly without needing to travel away towards the exit opening. Also, it is clear to see that the value of PMV and PDD in cases 2 and 3 were approximately the same value with only a very little difference between them; this was because that the difference of the extracted amount from the exit outlet and the HES system was a small for case 2 and same in case 3 . This will give the same behavior of the airflow and thermal indoor environment characteristics especially in the interesting area i.e. area near the occupant and near the proposed HES system. Similar results were revealed by Horikiri et al. (2015).

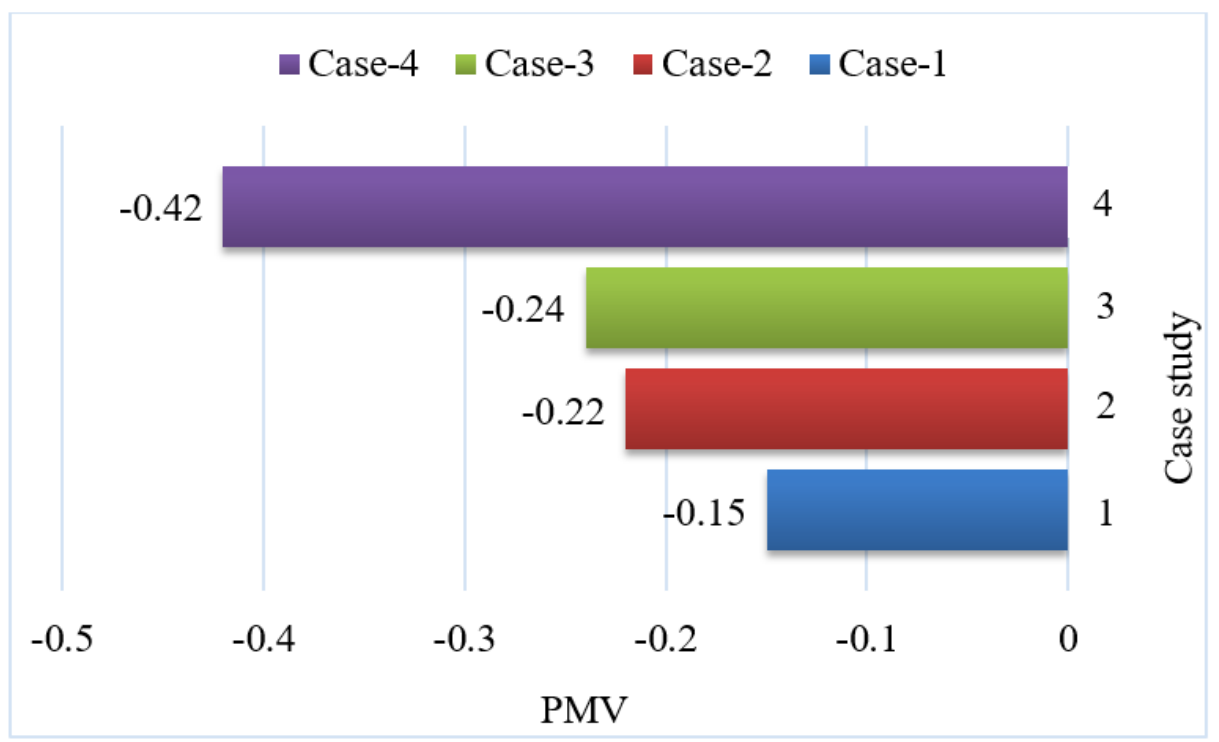

Fig. 5. Indoor thermal sensation PMV for each case study 
Ahmed et al., International Journal of Applied Science and Engineering, 18(6), 2021191

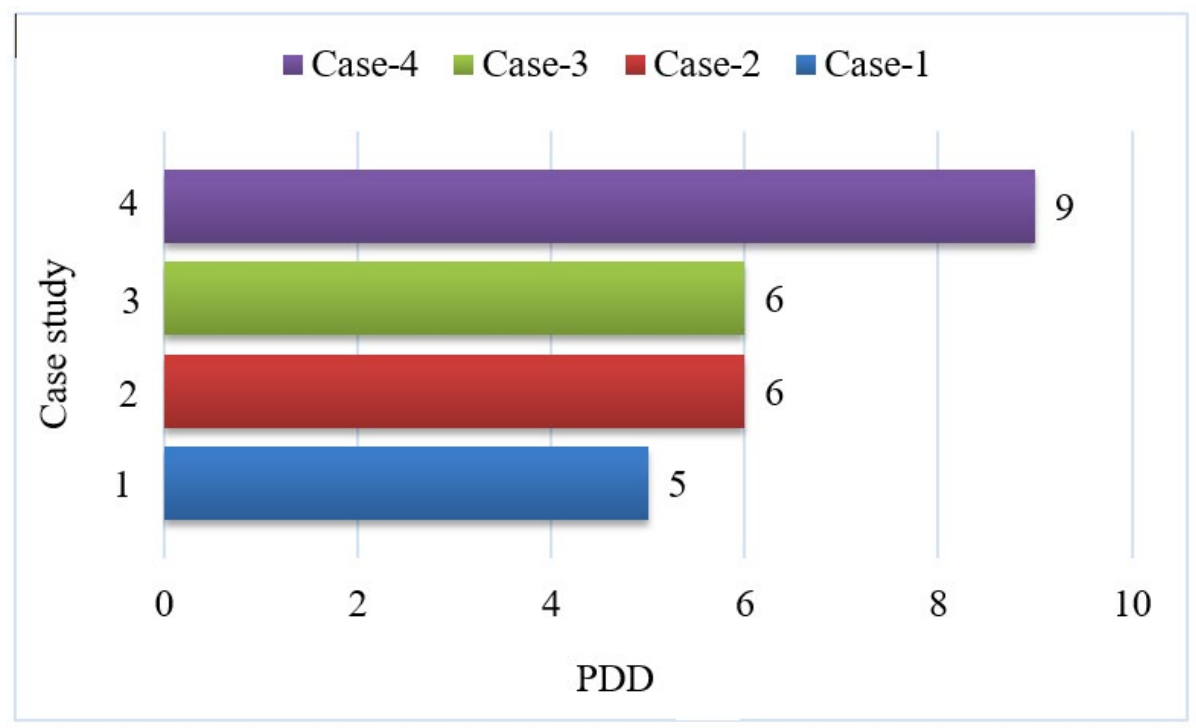

Fig. 6. Indoor thermal sensation PPD for each case study

5.2 Velocity and Temperature Distribution Evaluation

Temperature distribution in the domain can be considered one of the most important factors that have been greatly influenced by many parameters such as outlet locations, supply temperature, and internal heat source distribution. Also, the distribution of temperature has a great impact on indoor thermal comfort. Where the acceptable distribution of the temperature especially in the occupied area will improve the thermal environment and reduce the risk of thermal discomfort as well as enhancing the energy demand. In general, the locations of outlets and the amount of return and exit air have a direct impact to determine the behavior of air temperature distribution. Therefore, in this study, the effect of using HES system temperature distribution for a different amount of extraction air was evaluated for each case study. Fig. 7(a), (b), and (c) and (d) are the mid plane crossing the internal heat source and external wall at $\mathrm{x}=2.5$ $\mathrm{m}$ which are used to compare the temperature distribution for each case study. In case-1 when the HES system was not used, the temperature distribution in the domain was relatively high, ranged from $35.5^{\circ} \mathrm{C}$ to $45^{\circ} \mathrm{C}$, comparing with case 2, 3 and 4 especially in the area near the external wall. This was due to that in case 1 , the generated heat from the internal heat source needs more time to reach the outlet exit at ceiling level. This process will increase the room air temperature quickly comparing with other cases (case 2, 3, and 4 ). In case 2 and 3 , it can be noticed that the temperature distribution in the occupied zone and close to the external wall was relatively less than in case 1 . Where the temperature near the external wall ranged between $35^{\circ} \mathrm{C}$ to $42.5^{\circ} \mathrm{C}$ while in case 1 was ranged from $33.5^{\circ} \mathrm{C}$ to $45^{\circ} \mathrm{C}$. This was because these cases, the proposed HES system will extract the generated heat from the external warm air directly before mixing with the rest of the room air (see Fig. 6(b) and (c)). This will create a good distribution of temperature and enhancing the indoor environment. For case 4 when the exit opening was closed, the temperature distribution was increased compared with other cases study. This increase was due to that the heat comes from the internal heat source and from the external wall have only one way, HES system, to extract. This will lead an increase in the air temperature of the domain (see Fig. 7(d)). While in cases 2 and 3, the exit outlet was contributed to extract some amount of the generated heat. Therefore, the performance of the air temperature distribution was relatively low in case 4 comparing with other cases. For more details of the temperature behavior especially in the area near the external wall, four poles, pole, 2, 3 and 4, were employed to show the temperature profile near the external wall. Fig. 8(a), (b), (c), (d) and (e) show the measured poles locations and the temperature profile respectively. From these figures, it is clear to see that the temperature difference between the upper part and lower part of the room domain, the temperature distribution, for case 3 was the best compared with the other cases study. From these results, it can be concluded that the use an HES system with $15 \%$ of extract air will increase the ability to enhance the temperature distribution in line with improving the indoor thermal human comfort. While case 4 was the best for the thermal comfort only. 


\section{International Journal of Applied Science and Engineering}

Ahmed et al., International Journal of Applied Science and Engineering, 18(6), 2021191

Temperature ${ }^{\circ} \mathrm{C}$
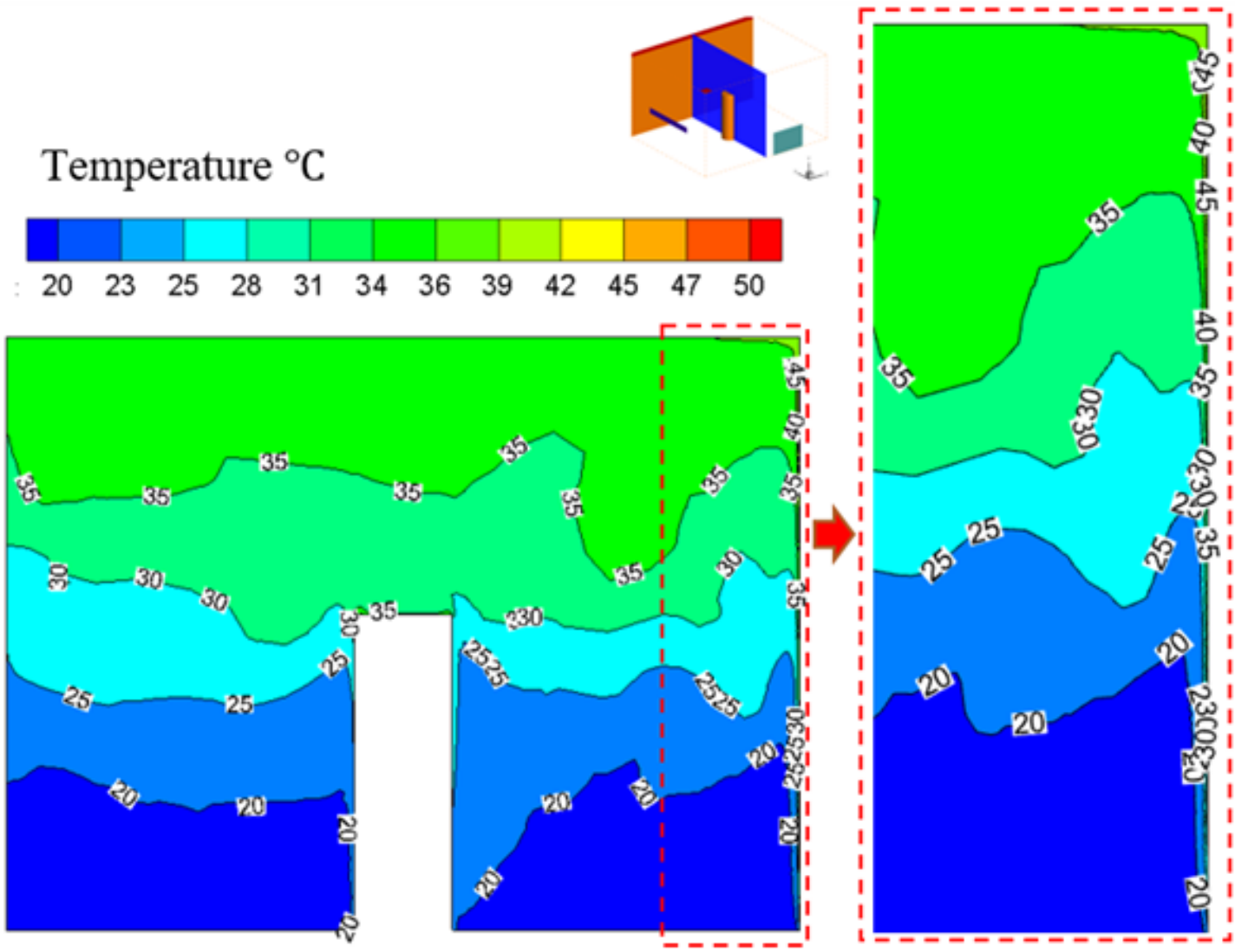

Temperature ${ }^{\circ} \mathrm{C}$
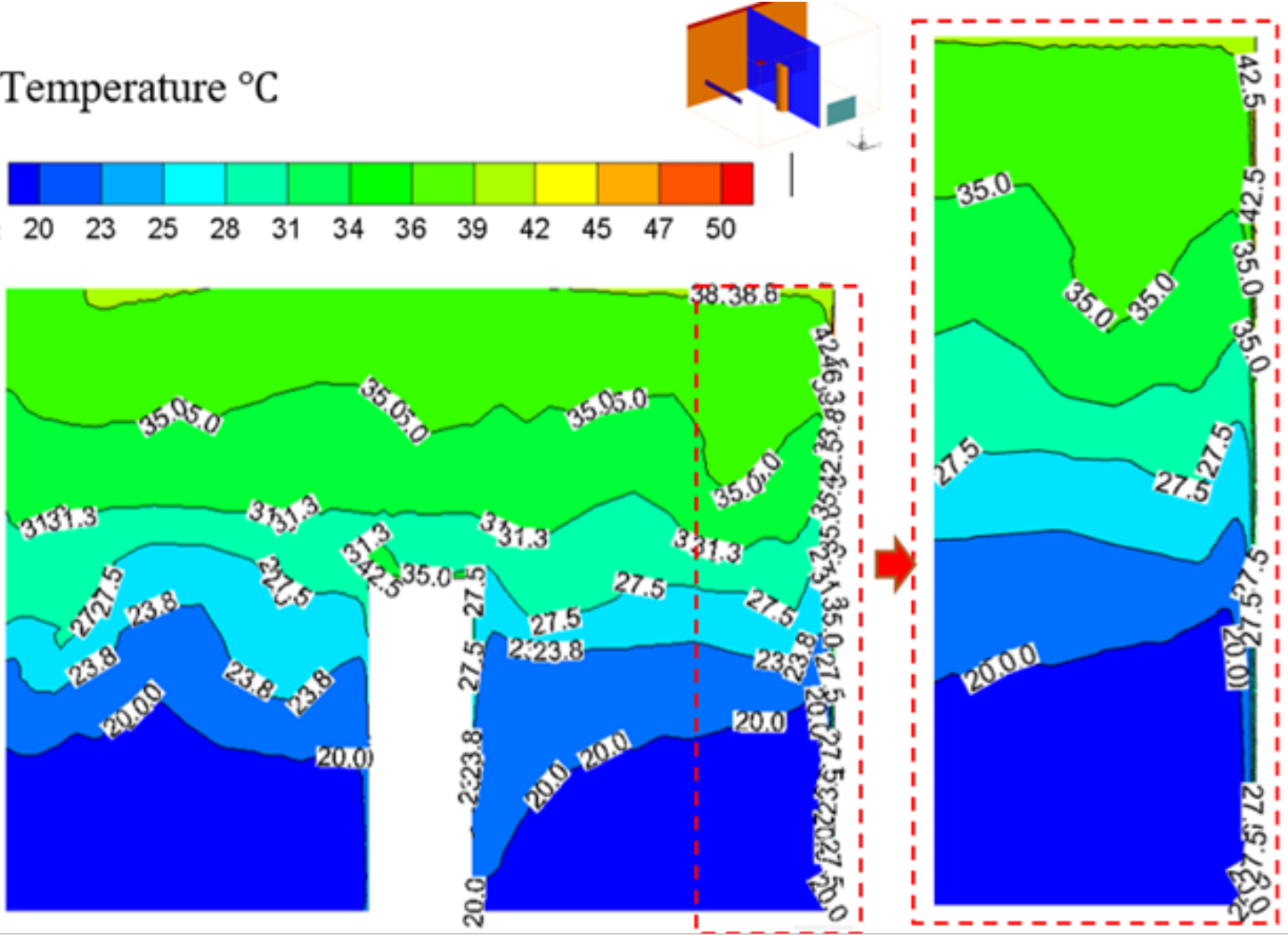

(b) 


\section{International Journal of Applied Science and Engineering}

Ahmed et al., International Journal of Applied Science and Engineering, 18(6), 2021191

।

Temperature ${ }^{\circ} \mathrm{C}$
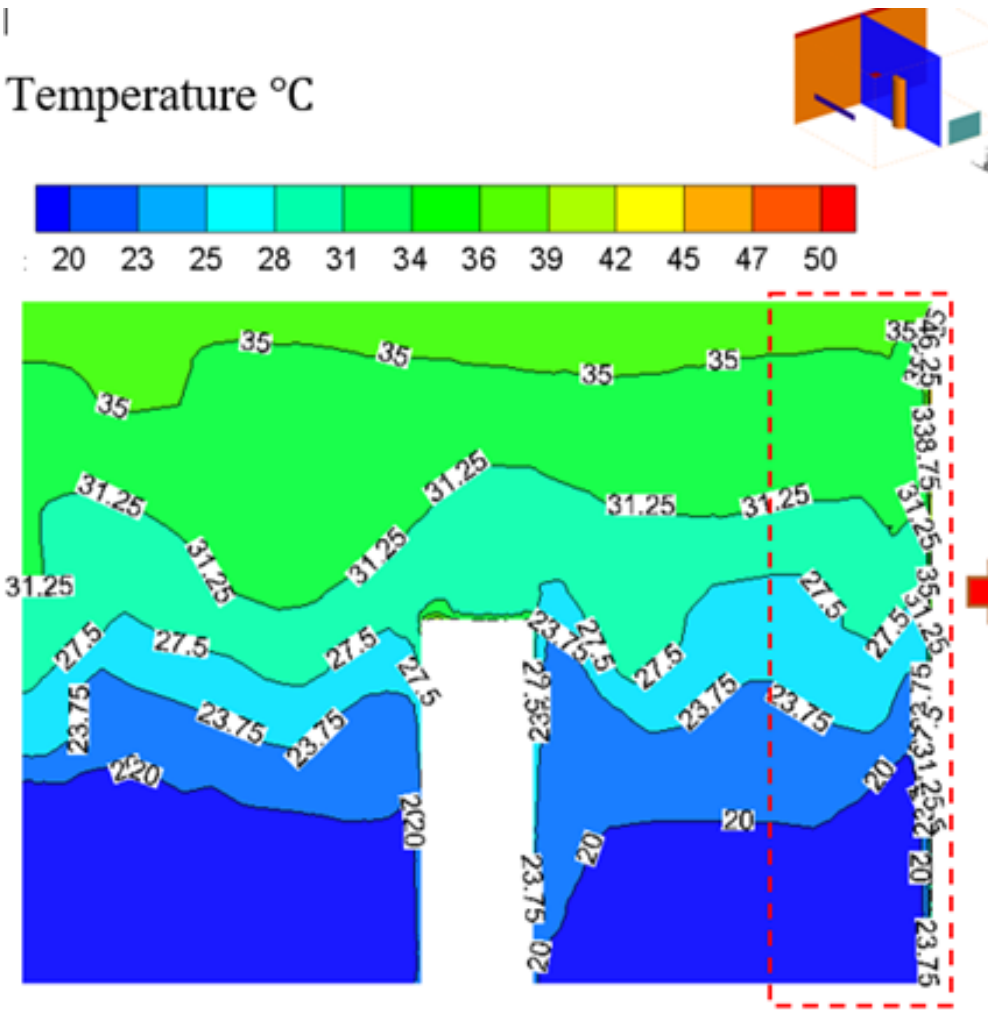

(c)

\section{Temperature ${ }^{\circ} \mathrm{C}$}
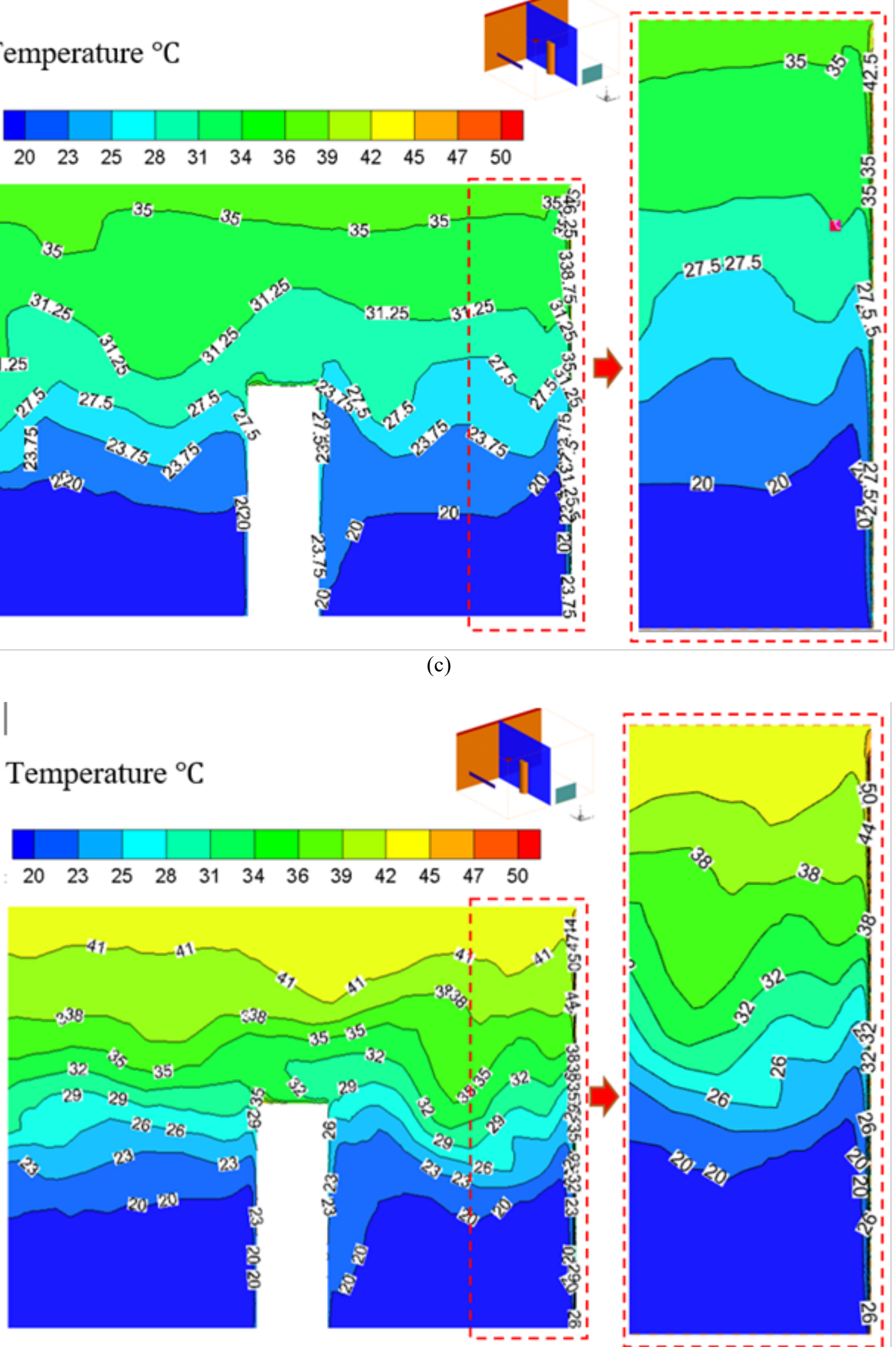

(d)

Fig. 7. Temperature distribution at the central section plane $x=2.5 \mathrm{~m}$ for all case study: (a) case-1; (b) case-2; (c) case-3; (d) case-4 


\section{International Journal of Applied Science and Engineering}

Ahmed et al., International Journal of Applied Science and Engineering, 18(6), 2021191

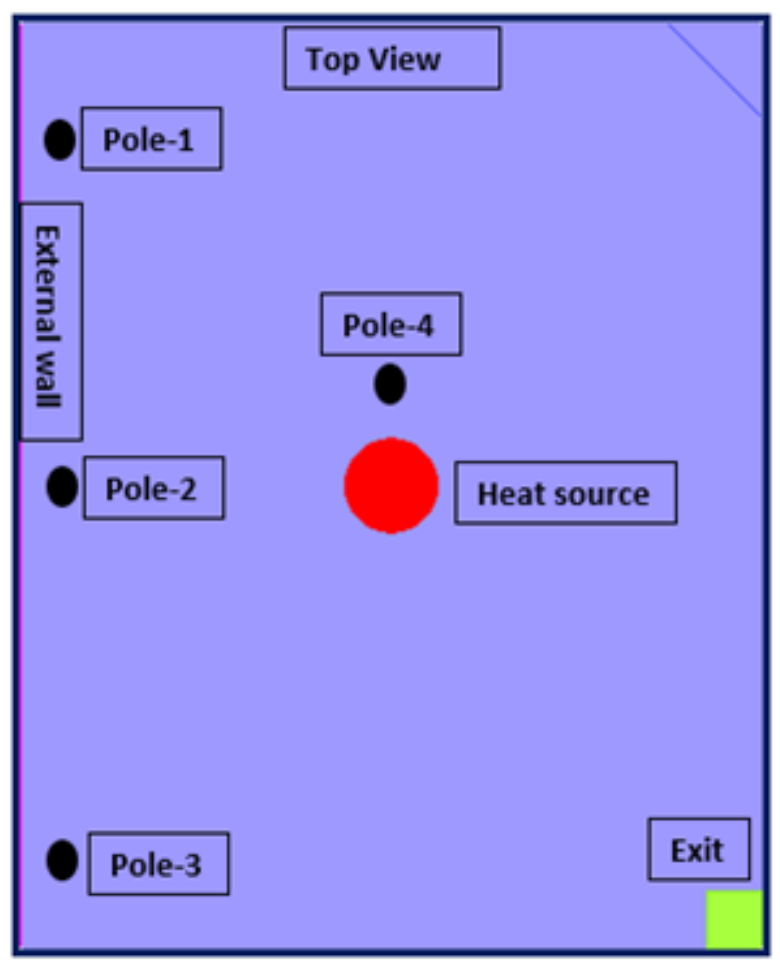

(a)

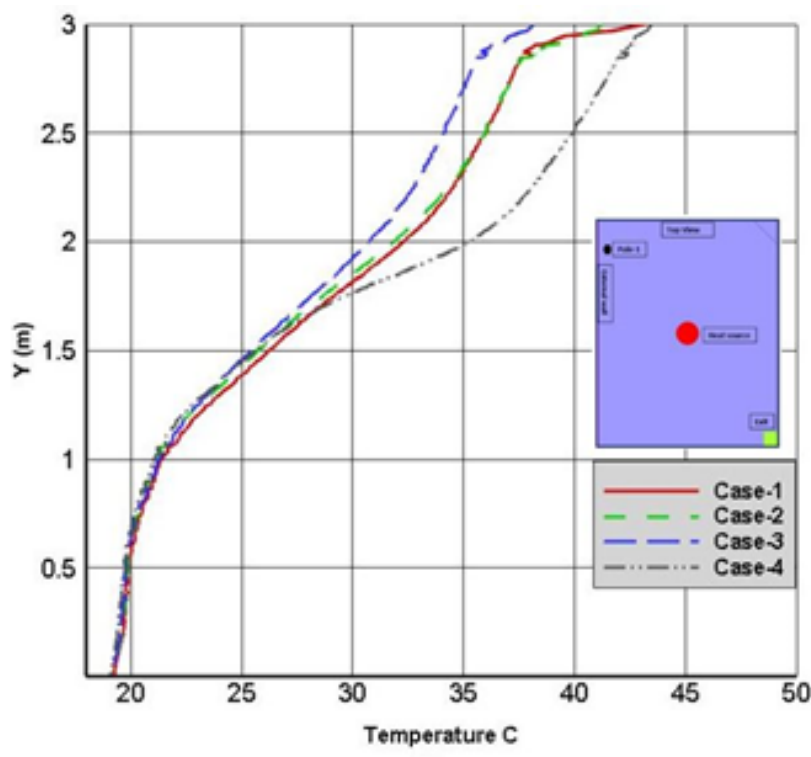

(b)

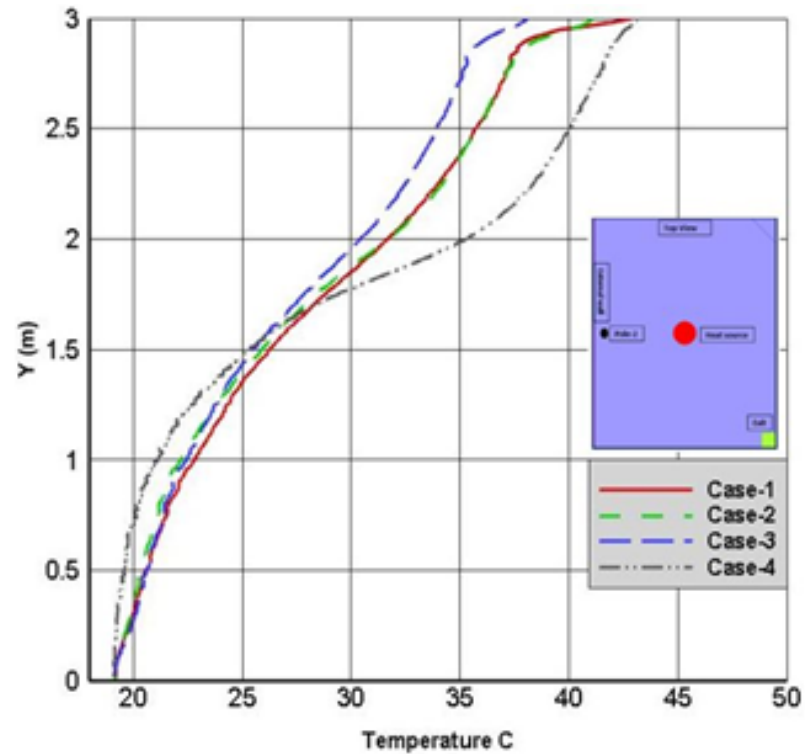

(c) 


\section{International Journal of Applied Science and Engineering}

Ahmed et al., International Journal of Applied Science and Engineering, 18(6), 2021191

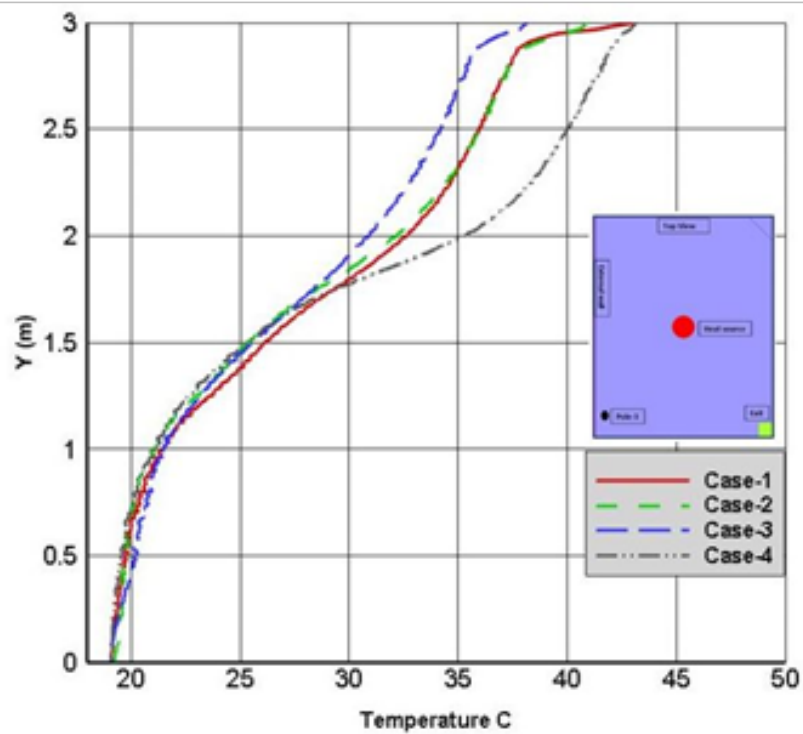

(d)

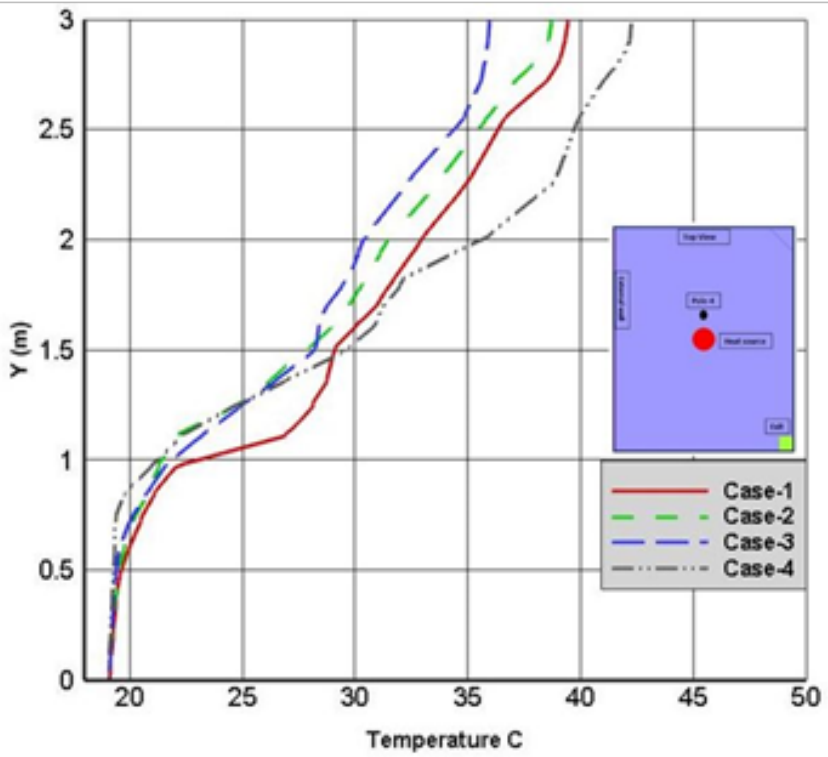

(e)

Fig. 8. Air temperature distribution for the vertical direction for all case study (a) measured monitoring pole locations; (b), (c), (d), and (e) are the vertical air temperature distribution in measured pole 1, 2, 3 and 4 respectively

\subsection{Local Human Thermal Discomfort}

It is very important to evaluate the temperature distribution in the vertical direction, especially for a stratified air distribution STARD system. In this system, a stratified air thermal will be formed in the room domain. The warm air will appear in the upper room part while the cold air layer will form in the lower room part near the floor level. A Noticeable difference will appear among these thermal layers. For this reason, the human thermal comfort regarding temperature differences between the head and foot level is highly requested for such a study. Depending on the standard of ASHRAE (Normalisation, 1994), the differences of the temperature between the head level, 1.3 $\mathrm{m}$ from the floor, and foot level, $0.1 \mathrm{~m}$ from floor level, should not be more than $3{ }^{\circ} \mathrm{C}$. Therefore, in this investigation, the temperature differences $\Delta \mathrm{T}_{\text {head-foot was evaluated for }}$ each case study. As shown in Fig. 8(a), pole -4 was used to measure the temperature differences at the occupant which is represented by the internal heat source (cylinder). Fig. 9

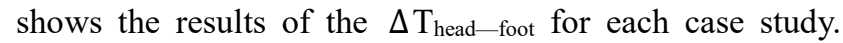
From this figure, it is clear to see that in case 1 when the system of HES was not used, the largest value of the $\Delta \mathrm{T}_{\text {head-foot }}$ was registered compared with other cases study. This was because that the generated heat will form a strong stratified thermal layer and this will increase the part of warmed air (upper room part) and increase the difference of temperature between the upper and lower part. In cases 2 and 4 , the $\Delta \mathrm{T}_{\text {head-foot }}$ was in acceptance range, less than 3 $\mathrm{C}$, while in case 3 the range was slightly large than $3 \mathrm{C}$. this was because that the extracted heat in case 2 was distributed between the exit and HES system with the relatively same amount. This will give more homogeneity of temperature air in the domain. In case 3, a large amount of non-equivalent amount of extracted air was extracted from the outlet opening. In case 4, when the room was served by the HES system only, all warmed air generated by the internal heat sources was extracted from the proposed system. This will enhance the vertical distribution of the temperature subsequently improve the thermal comfort regarding the $\Delta \mathrm{T}_{\text {head--foot. From }}$ these results, it can be concluded that the use of the HES system will highly improve the indoor thermal comfort regarding to the $\Delta \mathrm{T}_{\text {head}}-$ foot . 
Ahmed et al., International Journal of Applied Science and Engineering, 18(6), 2021191

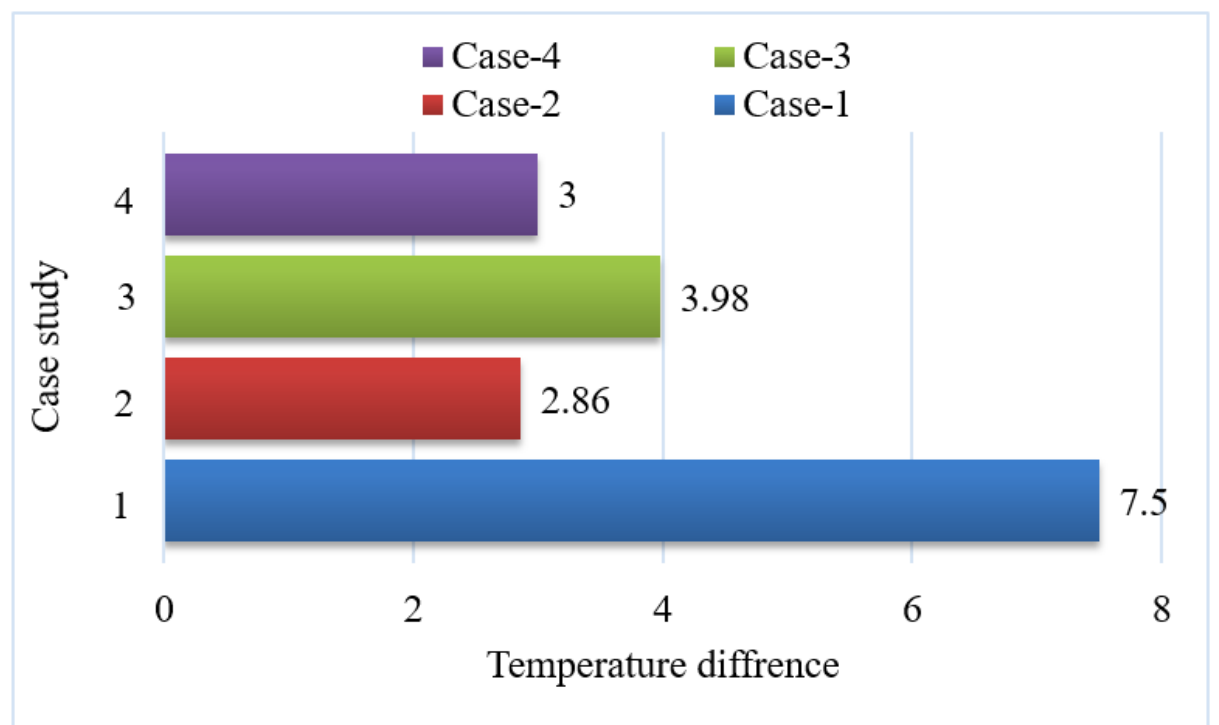

Fig. 9. Temperature differences ${ }^{\circ} \mathrm{C}$ between the head level and foot levels for each case study

\subsection{Evaluation of the Energy Saving}

In the room that served by a stratified air distribution (STRAD) system, only the region in the occupied area needed to be comfortable for the occupants. This will reduce the potential to increase the energy demand. For this system, due to the natural convection, the relatively cold supplied air moves up towards the ceiling level. This was because the temperature of the supply air will increase by contacting with the internal heat source and external wall and this will highly influence the amount of saving energy. Therefore, in this study, the amount of reducing energy demand on the cooling coil was evaluated for each case study. Cheng et al. (2013) proposed a method that depending on the CFD result to predict the reduction of the energy that demand by the cooling coil in a room that is served by the STRAD system. For the conditioned room that is served by STRAD system and has the same set temperature $\left(\mathrm{T}_{\text {set }}\right)$, the prediction of the load on the cooling coil is different from the room that uses the mixing ventilation (MV) system and can be expressed by Equations (5) and (6):

$\mathrm{Q}_{\text {coil-STRAD }}=\mathrm{Q}_{\text {coil-MV }}-\mathrm{c}_{\mathrm{p}} \times \dot{\mathrm{m}}_{\mathrm{e}} \times\left(\mathrm{T}_{\mathrm{e}}-\mathrm{T}_{\mathrm{set}}\right)$

$\mathrm{Q}_{\text {coil-MV }}=\mathrm{Q}_{\text {space }}+\mathrm{Q}_{\text {vent }}$

Where $Q_{\text {coil-STRAD }}$ is the cooling coil load for the room served by the STRAD system and $Q_{\text {coil-Mv }}$ the cooling coil load for the room served by the MV system respectively; $\mathrm{Q}_{\text {space }}$ is the space cooling coil load and $\mathrm{Q}_{\mathrm{vent}}$ is the room ventilation load. $\mathrm{T}_{\text {set }}$ represents the set room temperature which was equal to $24^{\circ} \mathrm{C}$ for each case study. While the amount of the reduction of cooling coil load, energy saving, was represented by the term of $c_{p} \times \dot{m}_{e} \times\left(T_{e}-T_{\text {set }}\right)$ which was employed in this investigation to show the influence of using the proposed HES system on the energy saving. Table 6 and Table 7 present the temperature at outlet opening for each case study and the energy saving respectively. Depending on the equation 7 , the temperature of the exit air plays a central role in saving energy. The amount of saving energy is increased by increasing of the air temperature at the air exit. As listed in Table 6, the value of air temperature at the HES system represents the maximum value, $\mathrm{T}_{\mathrm{HES}}$ ranged between $40.5^{\circ} \mathrm{C}$ to $46^{\circ} \mathrm{C}$, compared with the value of the air temperature at the exit outlet, $\mathrm{T}_{\mathrm{e}}$ ranged between $35.5^{\circ} \mathrm{C}$ to $38.06^{\circ} \mathrm{C}$, 46 . When the proposed HES system was not used as in case 1 , the amount of the cooling coil reduction was only $47.5 \%$. This means that the demand for energy was heights compared with other cases. In cases 2 and 3 the noticeable improvement of energy saving with $32 \%$ in case 2 and $42 \%$ in case 3 . This was because that in these cases the HES system may help to extrude a large amount of the generated air and subsequently increasing the air temperature at the exit and HES system outlet and this will enhance the amount of saving energy. Also, as presented in Table 6 and Table 7, the total energy saving in case 2 was better than in case 3 . This was because in case 2 the small amount of the extracted air across the HES system have a relatively long flow time comparing with case 3 (see Table 2). This will allow the extracted air in case 2 to be warmer than in case 3 . This will consequently improve the total energy saving. In case 4 , the energy saving evaluation was $57 \%$ of the total energy consumption. This amount of energy saving was the best compared with other case studies. In this case, the amount of exit air was the largest compared with other cases. This means that the maximum amount of the warmed exit air was extracted from the HES system only. Add to this, the HES system that located on the external wall will extract the heat generated by the warmest wall. For this reason, the amount of energy demand will be decreased significantly. From these results, it can be concluded that the HES system has a great impact on reducing the amount of energy demand in the room that served by the STRAD system. 
Ahmed et al., International Journal of Applied Science and Engineering, 18(6), 2021191

Table 6. Temperature at outlet opening for each case study

\begin{tabular}{cccc}
\hline Case study & $\mathrm{T}_{\mathrm{e}}$ & $\mathrm{T}_{\text {HES }}$ & $\mathrm{T}_{\mathrm{r}}$ \\
\hline Case-1 & 38.0 & - No HES & 26 \\
Case-2 & 38.06 & 41.2 & 25.4 \\
Case-3 & 35.5 & 40.5 & 25.0 \\
Case-4 & - No Exit & 43.0 & 20.3 \\
\hline
\end{tabular}

Table 7. Energy saving calculations

\begin{tabular}{|c|c|c|c|c|c|c|}
\hline \multirow[b]{2}{*}{$\begin{array}{l}\text { Case } \\
\text { study }\end{array}$} & \multicolumn{4}{|c|}{ Exit outlet } & \multicolumn{2}{|c|}{ HES system } \\
\hline & $\begin{array}{c}\dot{m e} \\
(\mathrm{~kg} / \mathrm{s})\end{array}$ & $\begin{array}{l}\Delta Q_{\text {coil }} C_{p} \times \dot{m e} \\
\times\left(T_{e}-T_{\text {set }}\right)\end{array}$ & $\Delta Q_{\text {coil }} / \Delta Q_{\text {space }} \%$ & $\dot{m e}(\mathrm{~kg} / \mathrm{s})$ & $\begin{array}{l}\Delta Q_{\text {coil }} C_{p} \times \dot{m e} \\
\times\left(T_{e}-T_{\text {set }}\right)\end{array}$ & $\Delta Q_{\text {coil }} / \Delta Q_{\text {space }} \%$ \\
\hline Case-1 & 0.049 & 0.68943 & 47.5 & 0 & 0 & 0 \\
\hline Case-2 & 0.0245 & 0.3462 & 23 & 0.0245 & 0.472752 & 32 \\
\hline Case-3 & 0.01225 & 0.14158 & 9.7 & 0.03675 & 0.609407 & 42 \\
\hline Case-4 & 0 & 0 & 0 & 0.049 & 0.8339 & 57 \\
\hline
\end{tabular}

\section{CONCLUSION}

In this investigation, the influence of using the proposed HES system and its relation to the amount of the extract air on energy consumption, temperature distribution and indoor thermal comfort were studied numerically. The results show that a significant enhancement in energy consumption and indoor thermal human comfort was made when the HES system was used with a high percentage of the extracted amount of air. This improvement was achieved in case 4 when the HES system exhausted a $20 \%$ from the total exit air and also in cases 2 and 3 when the HES system extract of $5 \%$ and $10 \%$ from the total exit air respectively. For case 4 , a $57 \%$ reduction of energy demand by a cooling coil. This is achieved when extracting the largest amount of exit air from the proposed HES system. Furthermore, in cases 2 and 3 when the HES system was used the cooling coil load was also reduced by $32 \%$ and $42 \%$ respectively.

For the indoor air environment, a homogeneous temperature distribution with an acceptable thermal comfort was found when the amount of extracted air was distributed between the exit outlet, exit and HES system, such as in cases 2 and 3. Overall, a significant enhancement of the energy saving with a good improvement of the indoor thermal environment was achieved by using the proposed HES system in the room that served by the STRAD system.

\section{ACKNOWLEDGEMENTS}

The authors would like to thank the Middle Technical University for the financial support of this project.

\section{REFERENCES}

Ahmed, A.Q. 2017. Modelling thermal comfort and energy saving enhancements in an office room served by stratified air distribution systems. University of Leicester.
Ahmed, A.Q., Gao, S. 2015. Thermal comfort and energy saving evaluation of a combined system in an office room using displacement ventilation. International Journal of Mechanical and Mechatronics Engineering, 9, 11011106.

Ahmed, A.Q., Gao, S. 2017. Numerical investigation of height impact of local exhaust combined with an office work station on energy saving and indoor environment. Building and Environment, 122, 194-205.

Ahmed, A.Q., Gao, S., Kareem, A.K. 2016. A numerical study on the effects of exhaust locations on energy consumption and thermal environment in an office room served by displacement ventilation. Energy Conversion and Management, 117, 74-85.

Ahmed, A.Q., GAO, S., Kareem, A.K. 2017. Energy saving and indoor thermal comfort evaluation using a novel local exhaust ventilation system for office rooms. Applied Thermal Engineering, 110, 821-834.

Ahn, B.-L., Kim, J.-H., Jang, C.-Y., Leigh, S.-B., Jeong, H. 2016. Window retrofit strategy for energy saving in existing residences with different thermal characteristics and window sizes. Building Services Engineering Research and Technology, 37, 18-32.

Al-Shohani, W.A.M., Ahmed, A.Q., Khaleel, A.J., Dakkama, H., Obaida, H.M., Fayyad, T.H. 2019. Energy saving by using a local ceiling spot air distribution system in an equipped office room. International Journal of Renewable Energy Research (IJRER), 9, 1976-1982.

Al-Shohani, W.A.M., Ahmed, A.Q., Khaleel, A.J., Dakkama, H., Obaida, H.M., Fayyad, T.H. 2020. Evaluation of using the ceiling and wall spots ventilation system on indoor thermal environment. IOP Conference Series: Materials Science and Engineering, IOP Publishing, 012056.

Chen, H., Moshfegh, B., Cehlin, M. 2013. Investigation on the flow and thermal behavior of impinging jet ventilation systems in an office with different heat loads. Building and Environment, 59, 127-144.

Cheng, Y., Niu, J., Liu, X., Gao, N. 2013. Experimental and numerical investigations on stratified air distribution 
systems with special configuration: Thermal comfort and energy saving. Energy and buildings, 64, 154-161.

Chiang, W.-H., Wang, C.-Y., Huang, J.-S. 2012. Evaluation of cooling ceiling and mechanical ventilation systems on thermal comfort using CFD study in an office for subtropical region. Building and Environment, 48, 113127.

Duan, Q., Wang, J. 2019. A parametric study of the combined effects of window property and air vent placement. Indoor and Built Environment, 28, 345-361.

Fanger, P.O. 1970. Thermal comfort. Analysis and applications in environmental engineering. Thermal comfort. Analysis and applications in environmental engineering.

Gan, G. 1995. Evaluation of room air distribution systems using computational fluid dynamics. Energy and buildings, 23, 83-93.

Gillingham, K., Newell, R.G., Palmer, K. 2009. Energy efficiency economics and policy. Annual Review of Resource Economics, 1, 597-620.

Hawendi, S., Gao, S., Ahmed, A.Q. 2019. Effect of heat loads and furniture on the thermal comfort of an isolated family house under a naturally ventilated environment. International Journal of Ventilation, 1-26.

Heidarinejad, G., Fathollahzadeh, M.H., Pasdarshahri, H. 2015. Effects of return air vent height on energy consumption, thermal comfort conditions and indoor air quality in an under floor air distribution system. Energy and Buildings, 97, 155-161.

Horikiri, K., Yao, Y., Yao, J. 2012. Numerical study of unsteady airflow phenomena in a ventilated room. ICHMT digital library online, Begel House Inc.

Horikiri, K., Yao, Y., Yao, J. 2014. Modelling conjugate flow and heat transfer in a ventilated room for indoor thermal comfort assessment. Building and Environment, 77, 135-147.

Horikiri, K., Yao, Y., Yao, J. 2015. Numerical optimisation of thermal comfort improvement for indoor environment with occupants and furniture. Energy and Buildings, 88, 303-315.

Kuo, J.-Y., Chung, K.-C. 1999. The effect of diffuser's location on thermal comfort analysis with different air distribution strategies. Journal of Thermal Envelope and Building Science, 22, 208-229.
Lam, J.C., Chan, A.L. 2001. CFD analysis and energy simulation of a gymnasium. Building and Environment, 36, 351-358.

Normalisation, O.I.D. 1994. Moderate thermal environments: Determination of the PMV and PPD indices and specification of the conditions for thermal comfort, International Organization for Standardization.

Park, H.-J., Holland, D. 2001. The effect of location of a convective heat source on displacement ventilation: CFD study. Building and environment, 36, 883-889.

Pérez-Lombard, L., Ortiz, J., Pout, C. 2008. A review on buildings energy consumption information. Energy and buildings, 40, 394-398.

Srebric, J., Chen, Q. 2002. Simplified numerical models for complex air supply diffusers. Hvac\&R Research, 8, 277294.

Vanhoutteghem, L., Skarning, G.C.J., Hviid, C.A., Svendsen, S. 2015. Impact of façade window design on energy, daylighting and thermal comfort in nearly zeroenergy houses. Energy and Buildings, 102, 149-156.

Wan, M., Chao, C. 2005. Numerical and experimental study of velocity and temperature characteristics in a ventilated enclosure with underfloor ventilation systems. Indoor air, 15, 342-355.

Xu, Y., Yang, X., Yang, C., Srebric, J. 2009. Contaminant dispersion with personal displacement ventilation, Part I: Base case study. Building and Environment, 44, 21212128.

Yakhot, V., Orszag, S., Thangam, S., Gatski, T., Speziale, C. 1992. Development of turbulence models for shear flows by a double expansion technique. Physics of Fluids A: Fluid Dynamics, 4, 1510-1520.

Yuan, X., Chen, Q., Glicksman, L.R., Hu, Y., Yang, X. 1999. Measurements and computations of room airflow with displacement ventilation. Ashrae Transactions, 105, 340. 